\title{
Maternal care influence on children's caries prevalence in southern Brazil
}

\section{Gabriela dos Santos PINTO Andréia Drawanz HARTWIG Raquel ELIAS \\ Marina Sousa AZEVEDO \\ Marília Leão GOETTEMS \\ Marcos Britto CORREA \\ Flávio Fernando DEMARCO}

Universidade Federal de Pelotas - UFPel, Graduate Program in Dentistry, Pelotas, RS, Brazil.
Declaration of Interests: The authors certify that they have no commercial or associative interest that represents a conflict of interest in connection with the manuscript.

\section{Corresponding Author:}

Gabriela dos Santos Pinto

E-mail:gabipinto@hotmail.com

Doi:10.1590/1807-3107BOR-2016.vol30.0070

Submitted: May 29, 2015

Accepted for publication: Mar 10, 2016

Last revision: Mar 31, 2016
Abstract: This study aimed to investigate the influence of specific maternal-factors on caries prevalence in offspring. This cross sectional study was conducted in Pelotas, Brazil nested in a cohort of adolescent mothers with children aged 24-42 months. A questionnaire was administered to collect information in relationship to socio-economic, demographic, and behavioral maternal variables. The outcome (children's dental caries prevalence $-\mathrm{dmfs}>0$ ) was collected from clinical examinations. Bivariate and multivariate analyses were conducted. A total of 538 mother/child dyads were evaluated and $15.1 \%$ of the children exhibited caries. Adjusted multivariate analysis showed children from mothers living without partners $(\mathrm{p}<0.027)$ had more caries than those living with partners. Maternal perception of a child's oral health was associated to occurrence of caries, particularly when mothers classified their child as poor and these children had a higher level of caries. In addition, mothers accurately evaluated their child's teeth when associated with caries occurrence. Maternal oral health care practices were associated with children's caries prevalence. Our results demonstrated mothers accurately evaluated the oral health of their offspring.

Keywords: Dental Caries; Maternal Behavior; Epidemiology.

\section{Introduction}

Dental caries remains the main chronic disease in childhood and it is considered a public health problem. ${ }^{1}$ Approximately $9 \%$ of the world's population exhibits untreated dental caries in primary teeth. ${ }^{2}$ Childhood caries is associated with dental pain, ${ }^{3}$ and dental fear, ${ }^{4}$ impacting negatively in children's quality of life. The last Brazilian national oral health survey ${ }^{5}$ showed a small decrease in dental caries prevalence at the age five, and there is an unequal distribution of the disease, with a low proportion of children exhibiting high disease levels, particularly those living in poverty. ${ }^{6}$

Even in those individuals living in unfavorable economic conditions, caries remains polarized, indicating other factors might be playing a role in dental caries development. ${ }^{7}$ Aspects related to familial environment and maternal behavior in relation to oral health have been associated with dental caries occurence. ${ }^{8}$ Hygiene oral habits, maternal caries experiences, maternal education levels, access to oral health services, and maternal perception of children's oral health are also related to caries prevalence in children. ${ }^{9}$

The occurrence of adolescent childbirth is a global phenomenon, most notably in low-income countries. According to the World Health 
Organization $(\mathrm{WHO}){ }_{1}^{10}$ annually, more than 14 million women between the ages of 15 and 19. In Brazil, 39 per 1,000 women aged $10-19$ had babies in $2006 .{ }^{11}$ Maternal age was also related to caries development in children, with mothers younger than age 23 presenting offspring with higher caries prevalence. Two probable explanations for this finding include less experience in younger mothers to care for their children's oral health needs and/or difficulties and lack of support younger mothers face in caring for their children properly..$^{12}$ Mattila et al. ${ }^{13}$ showed adolescent mothers were more prone to have children with poor oral health.

Therefore, it is necessary to generate scientific evidence to prevent increased caries prevalence in more vulnerable demographic groups during childhood. The objective of this study was to evaluate if specific maternal characteristics identified in adolescent mothers, including each mothers assessment of her child's oral health, could be associated with caries prevalence in her child.

\section{Methodology}

This cross-sectional study was nested in a cohort of adolescent mothers investigating mental disorders during pregnancy The present study was conducted in Pelotas, Southern Brazil, and the study participants, adolescent mothers aged 11-19, recruited from receiving pre-natal care from the National Public Health System (Sistema Único de Saúde - SUS). Children were born between 2009 and 2011 and the present study phase (Oral Health Survey) was performed when children were aged 24 and 42 months. More detail of the cohort design could be found elsewhere. ${ }^{14}$

The oral health survey included a questionnaire interview followed by clinical examination. The outcome, caries prevalence was obtained during child clinical evaluation using the dmfs (decayed, missing, filled surfaces) index, based on WHO guidelines. ${ }^{15}$ The required sample size was 320 children, considering a relative risk of $2.95 \%$, of confidence level and $80 \%$ power; and $63 \%$ caries prevalence at age 3 in children from adolescent mothers. ${ }^{11}$ Refusals and losses were compensated by including $15 \%$ more children, therefore a total sample size of 368 children and mother dyads were evaluated.

Caries experience was examined under field conditions using artificial light by five trained and calibrated examiners (Pediatric Dentistry post-graduates). The mean kappa for caries was 0.83 . The outcome was dichotomized at $\mathrm{dmfs}=0$ and $\mathrm{dmfs} \geq 1$ (presence of one or more caries lesions).

Independent variables were collected using questionnaires. The following variables were chosen: (1) maternal education level collected on years of study and dichotomized on $\leq 8$ years (elementary school) and $>8$ years (middle school or higher); (2) familial income in Brazilian minimum wages (Braziliancurrency) and later divided into tertiles; (3) marital classification, living or not living with a partner; (4) maternal occupation, yes or no; (5) principal child caregiver, mother or other. All the above variables were dichotomized, with the exception of (2), which was divided into tertiles as follows:

Maternal behavior variables and those related to their care with children oral health were also collected during the interview: (1) brushing frequency, $<1$ time per day or $\geq 1$ time per day; (2) receive help brushing teeth, no or yes; (3) maternal percepyion of child's oral health was collected based on a Likert scale(very good/good/regular/bad/very bad) and later dichotomized as two state data, good (very good or good) and poor (regular, bad, or very bad); and (4) has the mother ever examined her child's mouth (at least once or never).

Data were double typed and analyzed using Stata 12.0 (StataCorp. LP, College Station, USA) statistical software. The association between independent variables and the outcome was tested using a Chi-square test. In the multivariate analysis, a Poisson regression with robust variation was applied to estimate the prevalence ratio and the $95 \%$ confidence interval. The analysis was guided by a hierarchical model, with the first level containing the sociodemographic variables (education level, family income, having and occupation, and living with a partner) and the second level contained variables associated with hygiene and care (brushing frequency, brushing assistance, principal caregiver, maternal perception of child's oral health, mother's examination of her child's mouth). All relationships were adjusted by the covariables positioned in the same or superior level. A stepwise backward selection was used and only variables with $p \leq 0.25$ were maintained in the model. The significant level was set at 0.05

The Ethics Committee, Universidade Federal de Pelotas - UFPel approved the study (no. 194/2011). 
Mothers participating signed an informed consent. Children who required dental treatment were forwarded to the Basic Units or Pediatric Clinic - Dental School.

\section{Results}

From the initial sample of 831 adolescents recruited during pregnancy, 538 mother/child dyads were evaluated, with a response rate of $64.6 \%$. Mean maternal age was 20.1, more than one-half $(54 \% ; \mathrm{n}=291)$ lived with a partner and $63.5 \%(n=340)$ had occupation when interviewed. Mean child age was 31 months. Results indicated $15.1 \%$ of children showed evidence of previous dental caries. When caries experience was stratified we could observe that $11.4 \%$ up to 31 months old had already experienced dental caries, while 20.2\% of those children over 32 months exhibited caries. Bivariate analysis between independent variables and the outcome is shown in Table 1. Caries prevalence in children was significantly associated with mothers living without a partner $(p=0.026)$, maternal negative

Table 1. Association between caries experience in childhood and maternal socioeconomic and demographic characteristics, hygiene and care of mother in a sample adolescents in the city Pelotas, RS, Brazil, 2015.

\begin{tabular}{|c|c|c|c|c|}
\hline \multirow{3}{*}{ Variable/Category } & \multicolumn{4}{|c|}{ Caries experience in children } \\
\hline & \multicolumn{4}{|c|}{ dmfs $\leq 1, \mathrm{n}(\%)$} \\
\hline & Yes & No & Total & $\mathrm{p}$-value \\
\hline Total & $82(15.3)$ & $455(84.7)$ & 537 & - \\
\hline Maternal Occupation & & & & 0.825 \\
\hline Yes & $53(15.6)$ & $287(84.4)$ & $340(63.5)$ & - \\
\hline No & $29(14.9)$ & $166(85.1)$ & $195(36.5)$ & - \\
\hline Living with a partner & & & & $0.026^{*}$ \\
\hline Yes & $35(12.1)$ & $253(87.9)$ & $288(53.9)$ & - \\
\hline No & $47(19.1)$ & $199(80.9)$ & $246(46.1)$ & - \\
\hline Family income & & & & 0.106 \\
\hline 1st Tertile & $29(16.02)$ & $150(83.8)$ & $179(34.6)$ & - \\
\hline 2nd Tertile & $30(17.8)$ & $139(82.2)$ & $169(32.7)$ & - \\
\hline 3th Tertile & $17(10.06)$ & $152(89.3)$ & $169(32.7)$ & - \\
\hline Mother's education level (yrs) & & & & 0.324 \\
\hline$\leq 8$ & $39(13.7)$ & $245(86.3)$ & $284(53.2)$ & - \\
\hline$>8$ & $42(16.8)$ & $208(83.2)$ & $250(46.8)$ & - \\
\hline Brushing frequency & & & & 0.070 \\
\hline Less than 1 time a day & $51(62.20)$ & $328(72.09)$ & $379(70.6)$ & - \\
\hline Brush once a day or more & $31(37.80)$ & $127(27.91)$ & $158(29.4)$ & - \\
\hline Child receive help to brushing their teeth & & & & 0.143 \\
\hline No & $18(22.2)$ & $71(15.6)$ & $89(16.6)$ & - \\
\hline Yes & $63(77.8)$ & $383(84.4)$ & $446(83.4)$ & - \\
\hline Who is the main caregiver & & & & 0.092 \\
\hline Mother & $71(16.6)$ & $357(83.4)$ & $428(79.7)$ & - \\
\hline Other & $11(10.9)$ & 98 (89.9) & $110(20.3)$ & - \\
\hline Maternal perception on child's oral health & & & & $<0.001^{*}$ \\
\hline Very good / good & $44(9.6)$ & $415(90.4)$ & $459(85.6)$ & - \\
\hline Fair / poor / very poor & $37(48.0)$ & $40(52.0)$ & $77(14.4)$ & - \\
\hline Maternal examination of the child's mouth & & & & $<0.001^{*}$ \\
\hline At least once & 64 (13.3) & $418(86.7)$ & $482(89.9)$ & - \\
\hline Never & $17(31.5)$ & 37 (68.5) & $54(10.1)$ & - \\
\hline
\end{tabular}

dmfs: decayed, missing, filled surfaces; ${ }^{*}$ Chi-square $(X 2)$ test. 
perception of child's oral health ( $\mathrm{p}<0.001)$, and mother's examination of her child's mouth $(\mathrm{p}<0.001)$.

Multivariate analysis results, following adjustments, indicated children from mothers living without a partner exhibited $\sim 60 \%$ higher probability of exhibiting dental caries compared with children from mothers living with partners [Prevalence Ratio: PR $=1.62$ (95\%CI 1.04-2.52)] (Table 2). Mothers with a negative perception of their child's oral health showed children with an over four and one half times $[(\mathrm{PR}=4.60(95 \% \mathrm{CI} 2.94-7.19)]$ increased probability of dental caries compared with mothers who positively evaluated their offspring's oral health. Children exhibited more caries [(PR $=1.72(95 \% \mathrm{CI} 1.00-2.96)]$ when mothers had never examined their child's mouth. Adjustments were performed for the following socio-economic variables: (1) mother's education level; (2) family income; (3) presence or absence of a partner; and (4) mother's occupation outside the home. Adjustments were performed for the following hygiene variables: (1) child's brushing frequency; and (2) adult assistance brushing child's teeth. Adjustments were performed for the following maternal-child care variables: (1) who is the principal child caregiver;

Table 2. Crude and adjusted analyzes for variables socioeconomic characteristics and maternal demographic, hygiene, care and caries experience in children in a mother sample adolescents in the city of Pelotas, RS, Brazil, 2015.

\begin{tabular}{|c|c|c|c|c|c|c|}
\hline \multirow{3}{*}{ Variable/Category } & \multicolumn{6}{|c|}{ Caries experience in children } \\
\hline & \multicolumn{6}{|c|}{ dmfs $\geq 1, n(\%)$} \\
\hline & $\mathrm{PR}^{\mathrm{B}}$ & $95 \% \mathrm{Cl}$ & $p$-value & $\mathrm{PR}^{\mathrm{A}}$ & $95 \% \mathrm{Cl}$ & $p$-value \\
\hline Maternal Occupation & - & - & 0.831 & - & - & - \\
\hline Yes & 1 & - & - & - & - & - \\
\hline No & 1.05 & $0.69-1.59$ & - & - & - & - \\
\hline Living with a partner & - & - & 0.029 & - & - & 0.144 \\
\hline Yes & 1 & - & - & 1 & - & - \\
\hline No & 1.57 & $1.05-2.35$ & - & 1.62 & $1.04-2.52$ & $0.032^{*}$ \\
\hline Family income & - & - & 0.095 & - & - & 0.098 \\
\hline 1st Tertile & 1 & - & - & 1 & - & - \\
\hline 2nd Tertile & 1.09 & $0.69-1.74$ & - & 1.04 & $0.66-1.67$ & - \\
\hline 3rd Tertile & 0.62 & $0.35-1.09$ & - & 0.63 & $0.36-1.09$ & - \\
\hline Mother's education level (yrs) & - & - & 0.347 & - & - & - \\
\hline$>8$ & 1 & - & - & - & - & - \\
\hline$\leq 8$ & 1.21 & $0.81-1.81$ & - & - & - & - \\
\hline Brushing frequency & - & - & 0.103 & - & - & - \\
\hline Less than 1 time a day & 1 & - & - & - & - & - \\
\hline Do not brush every day & 0.68 & $0.43-1.07$ & - & - & - & - \\
\hline \multicolumn{7}{|l|}{ Who performs brushing } \\
\hline Child receive help to brushing their teeth & - & - & 0.194 & - & - & - \\
\hline No & 1 & - & - & - & - & - \\
\hline Yes & 0.69 & $0.41-1.18$ & - & - & - & - \\
\hline \multicolumn{7}{|l|}{ Who is the main caregiver } \\
\hline Mother & 1 & - & - & 1 & - & - \\
\hline Other & 0.77 & $0.56-1.06$ & 0.096 & 0.82 & $0.59-1.13$ & 0.22 \\
\hline \multicolumn{7}{|l|}{ Maternal perception on child's oral health } \\
\hline Very good / good & 1 & - & - & 1 & - & - \\
\hline Fair / poor / very poor & 5.01 & $3.24-7.76$ & $<0.001$ & 4.60 & $2.94-7.19$ & $<0.001^{*}$ \\
\hline \multicolumn{7}{|l|}{ Maternal examination of the child's mouth } \\
\hline At least once & 1 & - & - & 1 & - & - \\
\hline Never & 2.37 & $1.38-4.05$ & 0.003 & 1.72 & $1.00-2.96$ & 0.05 \\
\hline
\end{tabular}

*Variables that presented a $p$-value $\geq 0.25$ were not included in the final model after the adjustment. PR: Prevalence ratio; Cl: Confidence Interval;

C: Crude analysis; A: Adjusted analysis; dmfs: decayed, missing, filled surfaces. 
(2) maternal perception of child's oral health; and (3) mother's examination of her child's mouth.

\section{Discussion}

The overall results of our study demonstrated specific attributes (e.g. socio-economic) and behavior (e.g. childcare) of adolescent mothers influenced their offspring's oral health. Some factors are already known to cause dental caries, including the a lack of oral hygiene and diets high in sucrose are well known factors leading to dental caries disease. ${ }^{16}$ However, behavioral variables are likely to play an important role in caries development, particularly due to a mother's influence on her children. In many countries and under certain socio-economic conditions, a mother remains the primary caregiver of young children, and this maternal role establishes children's behavior towards oral health, which can influence children's caries risk..$^{17} \mathrm{~A}$ lower level of dental caries was observed in children when mothers evaluated their child's oral health positively; mothers examined their child's mouth; and mothers lived with a partner. Adolescence is a critical period when behaviors are established for adult life and teenagers are questioning their future. At this age, adolescents generally exhibit less care for their own health. Therefore, pregnancy in an adolescent might result in harmful behavior in relationship to the teenager's own health as well as her offspring's. ${ }^{12,28}$ This emphasizes the importance of our study, which investigated the impact of adolescent pregnancy on a child's oral health.

The presence of a partner living with the adolescent mother exhibited a positive impact on children's oral health and this might be associated with enhanced stimulation to perform daily activities in a familial environment. ${ }^{18} \mathrm{~A}$ partner present with a young mother can help share in the offspring's care, including oral hygiene care. The absence of a partner can compromise maternal mental health, leading to emotional and behavioral problems for the mother and often the child, as this acts as a risk factor for cognitive child development and reduces preventive health care, including oral hygiene. ${ }^{19}$ The absence of a partner can contribute to maternal depression, ${ }^{20}$ which is associated with an increased risk of children developing dental caries, ${ }^{21}$ since maternal depression reduces the care dedicated to a child..$^{22}$

An important inference of our study was the adolescent mothers' care of their children's oral health was associated with their children's caries activity. The strongest effect observed was related to maternal perception of children's oral health. When adolescent mothers reported their children's oral health as good/very good, the children exhibited low levels of dental caries; however when adolescent mothers evaluated their children's oral health as poor, children showed higher levels of caries. Indeed, a recent study of low income families in Italy showed maternal perception of a child's oral health was the only variable consistently associated with caries prevalence in children. ${ }^{23}$ Camargo et al. ${ }^{24}$ showed mothers reporting their children's oral health as good/very good were associated with an increased number of visits to dental services, particularly preventive or routine appointments. These results demonstrated higher concerns and knowledge regarding oral health, likely reflecting more care devoted to their children's dental care, leading to decreased chances for these children to develop dental diseases during childhood. In contrast, if the mother described her child's oral health as poor, it might indicate a lowered concern regarding her child's oral health. However, parents who accurately evaluated their children's oral health condition might also more readily understand his or her needs and search for early treatment. ${ }^{24}$ Maternal perception of child oral health and dental caries severity ${ }^{25}$ might represent an easy, fast, effective and low cost approach to obtain reliable information in planning oral health public policy. These data are vital when epidemiological surveys with clinical examinations performed by dentists are not feasible due to financial limitations or when locales with available dentists in sufficient number are unavailable. ${ }^{26}$

Furthermore, our results showed a positive association between adolescent mothers who examined their children's mouth and lower levels of dental caries in their children. A mother concerned with her own oral health would likely take better care of her child's oral health, ${ }^{23}$ which would include the examination of her child's mouth and teeth. Such an examination is likely to detect any 
dental problems, leading to an early dentist visit for preventive or therapeutic measurements. This finding also emphasizes the importance of professionals instructing adolescent mothers regarding the importance of examining their children's mouth. Information related to the development of dental caries and effective prevention methods should be provided. In this way, mothers can be proactive participants in promoting their children's oral health.

It is important to highlight certain particularities from our study. We included only adolescent mothers (aged 17-22) and therefore, our opportunity to conduct a long-term study was limited. All adolescent were recruited from the National Public Health System (Sistema Único de Saúde - SUS). Therefore, our sample group shared a common low socio-economic profile, which might be considered a limitation of our study. The literature provided strong evidence that socioeconomic status was related to caries occurrence, ${ }^{6,27,28,29}$ and we were not able to find association with socioeconomic level and caries occurrence in the present study, probably because this cohort is not a populational sample, and the similarity in low schooling and income could explain the lack of such association. The cohort examined in the present study was not representative of the population and the similarity in minimal education and low income might explain the absence of association. Our study limitations also included those inherent to a cross-sectional study design, which required primary caregivers to provide retrospective reports on how they administered oral health preventive care to their child. Moreover, this study relied on maternal self-reporting data and therefore risked bias, with mothers reporting socially desirable behaviors. However, self-reporting data are a reasonable proxy measurement with predictive validity for child outcomes. The strengths of our study should be emphasized, including the elegant methodological design and the appropriate statistical analyses, with a sufficient sample size, evaluating mothers and children.

A mother's perception of her child's overall health, including oral health can be vital in identifying children more vulnerable to dental caries during childhood. However, there is a need to develop preventive educational programs to empower mothers with the knowledge of dental caries disease and effective methods for its prevention. Such approaches can result in healthy habits during early childhood, ${ }^{27}$ which have positive effects throughout life. ${ }^{30}$

\section{Conclusion}

Our results demonstrated adolescent mothers exhibited certain behavioral attributes, which impacted the development of dental caries in their children. Adolescent mothers living with a partner, those having a positive perception of their child's oral health, and mothers who had examined their child's mouth and teeth were associated with children exhibiting lower caries prevalence.

\section{Acknowledgements}

The authors would like to thank the State Funding Agency (Fundação de Amparo à Pesquisa do Estado do Rio Grande do Sul - FAPERG) for the grant (no. 11/1189-4) that allowed this study to be performed, given to the PI (Flávio Fernando Demarco). Also, we would like to thank FAPERGS for the scholarship given to the first author (Gabriela dos Santos Pinto). The authors are grateful to the graduate and undergraduate students that participate in the fieldwork. We would like to thank the Universidade Católica de Pelotas - UCPel staff for their collaboration as well as the Post-Graduate Program in Health in Behavior for the assistance.

\section{References}

1. Do LG, Scott JA, Thomson WM, Stamm JW, RuggGunn AJ, Levy SM, et al. Common risk factor approach to address socioeconomic inequality in the oral health of preschool children-a prospective cohort study. BMC Public Health. 2014;14(1):429. doi:10.1186/1471-2458-14-429
2. Marcenes W, Muirhead VE, Murray S, Redshaw P, Bennett $\mathrm{U}$, Wright D. Ethnic disparities in the oral health of three- to four-year-old children in East London. Br Dent J. 2013;215(2):E4. doi 10.1038/sj.bdj.2013.687

3. Boeira GF, Correa MB, Peres KG, Peres MA, Santos IS, Matijasevich A, et al. Caries is the main cause for dental 
pain in childhood: findings from a birth cohort. Caries Res. 2012;46(5):488-95. doi:10.1159/000339491

4. Torriani DD, Goettems ML, Cademartori MG, Fernandez RR, Bussoletti DM. Representation of dental care and oral health in children's drawings. Br Dent J. 2014;216(12):E26. doi:10.1038/sj.bdj.2014.545

5. Brasil. Ministério da Saúde. Pesquisa Nacional de Saúde Bucal: Projeto SB Brasil 2010 - Resultados principais. Brasília (DF): Ministério da Saúde; 2011.

6. Ardenghi TM, Piovesan C, Antunes JLF. Inequalities in untreated dental caries prevalence in preschool children in Brazil. Rev Saude Publica. 2013;47 Suppl 3:129-37. doi:10.1590/S0034-8910.2013047004352

7. Nunes AMM, Silva AAM, Alves CMC, Hugo FN, Ribeiro CCC. Factors underlying the polarization of early childhood caries within a high-risk population. BMC Public Health [Internet]. 2014 Sep 22 [cited 2016 Mar 30];14:988. Available from: http://bmcpublichealth. biomedcentral.com/articles/10.1186/1471-2458-14-988 doi:10.1186/1471-2458-14-988

8. Castilho ARF, Mialhe FL, Barbosa TS, Puppin-Rontani RM. Influence of family environment on children's oral health: a systematic review. J Pediatr (Rio J). 2013;89(2):116-23. doi:10.1016/j.jped.2013.03.014

9. Freitas SFT, Lacerda JT, Neumann SRB. Severidade da cárie dentária e fatores associados em escolares da rede pública de Joinville, Santa Catarina. Pesqui Bras Odontopediatria Clin Integr. 2013;13(4):303-8. doi:10.4034/PBOCI.2013.134.01

10. World Health Organization. Pregnant adolescents: delivering on global promises of hope. Geneva: WHO Document Production Services; 2006.

11. Brasil. Ministério da Saúde. Pesquisa Nacional de Demografia e Saúde da Criança e da Mulher. Brasília (DF): Ministério da Saúde; 2006.

12. Niji R, Arita K, Abe Y, Lucas ME, Nishino M, Mitome M. Maternal age at birth and other risk factors in early childhood caries. Pediatr Dent. 2010;32(7):493-8.

13. Mattila ML, Rautava $P$, Ojanlatva A, Paunio $P$, Hyssälä L, Helenius $\mathrm{H}$, et al. Will the role of family influence dental caries among seven-year-old children? Acta Odontol Scand. 2005;63(2):73-84. doi:10.1080/00016350510019720

14. Coelho FMC, Pinheiro RT, Silva RA, Quevedo LA, Souza LDM, Matos MB, et al. Parental bonding and suicidality in pregnant teenagers: a population-based study in southern Brazil. Soc Psychiatry Psychiatr Epidemiol. 2014;49(8):1241-8. doi:10.1007/s00127-014-0832-1

15. World Health Organization. Oral health surveys: basic methods. 4th ed. Geneva: WHO; 1997.

16. Warren JJ, Weber-Gasparoni K, Marshall TA, Drake DR, Dehkordi-Vakil F, Dawson DV, et al. A longitudinal study of dental caries risk among very young low SES children. Community Dent Oral Epidemiol. 2009;37(2):116-22. doi:10.1111/j.1600-0528.2008.00447.x
17. Almeida TF, Vianna MI, Cabral MB, Cangussu MC, Floriano FR. Family context and incidence of dental caries in preschool children living in areas covered by the Family Health Strategy in Salvador, Bahia State, Brazil. Cad Saude Publica. 2012;28(6):1183-95. doi:10.1590/S0102-311X2012000600017

18. Andrade SA, Santos DN, Bastos AC, Pedromônico MRM, Almeida-Filho N, Barreto ML. Family environment and child's cognitive development: an epidemiological approach. Rev Saude Publica. 2005;39(4):606-11. doi:10.1590/S0034-89102005000400014

19. Kavanaugh M, Halterman JS, Montes G, Epstein M, Hightower AD, Weitzman M. Maternal depressive symptoms are adversely associated with prevention practices and parenting behaviors for preschool children. Ambul Pediatr. 2006;6(1):32-7. doi:10.1016/j.ambp.2005.09.002

20. Pascoe JM, Stolfi A, Ormond MB. Correlates of mothers' persistent depressive symptoms: a national study. J Pediatr Health Care. 2006;20(4):261-9. doi:10.1016/j.pedhc.2006.01.006

21. D’Alessandro G, Cremonesi I, Alkhamis N, Piana G. Correlation between oral health in disabled children and depressive symptoms in their mothers. Eur J Paediatr Dent. 2014;15(3):303-8.

22. Chung EK, McCollum KF, Elo IT, Lee HJ, Culhane JF. Maternal depressive symptoms and infant health practices among low-income women. Pediatrics. 2004;113(6):e523-9. doi:10.1542/peds.113.6.e523

23. Moimaz SAS, Fadel CB, Lolli LF, Garbin CAS, Garbin AJI, Saliba NA. Social aspects of dental caries in the context of mother-child pairs. J Appl Oral Sci. 2014;22(1):73-8. doi:10.1590/1678-775720130122

24. Camargo MBJ, Barros AJD, Frazão P, Matijasevich A, Santos IS, Peres MA, et al. Predictors of dental visits for routine check-ups and for the resolution of problems among preschool children. Rev Saude Publica 2012;46(1):87-97. doi:10.1590/S0034-89102012005000004

25. Talekar BS, Rozier RG, Slade GD, Ennett ST. Parental perceptions of their preschool-aged children's oral health. J Am Dent Assoc. 2005;136(3):364-72. doi:10.14219/jada.archive.2005.0179

26. Freitas CHSM, Sampaio FC, Roncalli AG, Moysés SJ. Methodological discussion about prevalence of the dental fluorosis on dental health surveys. Rev Saude Publica. 2013;47 Suppl 3:138-47. doi:10.1590/S0034-8910.2013047004359

27. Oliveira LJ, Correa MB, Nascimento GG, Goettems ML, Tarquíni SB, Torriani DD, et al. Inequalities in oral health: are schoolchildren receiving the Bolsa Família more vulnerable? Rev Saude Publica. 2013;47(6):1039-47. doi:10.1590/S0034-89102013000901039

28. Peres KG, Cascaes AM, Leão ATT, Côrtes MIS, Vettore MV. Sociodemographic and clinical 
- Maternal care influence on children's caries prevalence in southern Brazil

aspects of quality of life related to oral health in adolescents. Rev Saude Publica. 2013;47 Suppl 3:19-28. doi:10.1590/S0034-8910.2013047004361

29. Tinanoff N, Reisine S. Update on early childhood caries since the Surgeon General's Report. Acad Pediatr. 2009;9(6):396-403. doi:10.1016/j.acap.2009.08.006
30. Demarco FF, Peres KG, Peres MA. Life course epidemiology and its implication for oral health. Braz Oral Res [Internet]. 2014 [cited 2016 Mar 30];28(1):1-2. Available from: http://www.scielo.br/scielo. php?script=sci_arttext\&pid=S1806-83242014000100002 doi:10.1590/S1806-83242014.50000006 